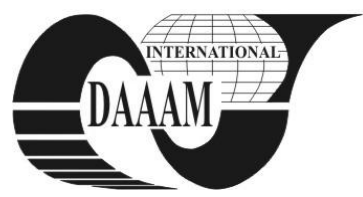

\title{
THE USE OF SIX SIGMA METHOD WITHIN THE FRAMEWORK OF ENVIRONMENTAL MANAGEMENT
}

\author{
KRALIKOVA, R[uzena]; WESSELY, E[mil] \& RUSKO, M[iroslav]
}

\begin{abstract}
The Six Sigma method is whole and flexible system of achieving, maintaining and maximizing of the business success. Six Sigma is based mainly on understanding of the needs and customer expectation, disciplined facts use, statistics analyze and on the base of responsible accsess to management, improving and creating new business, manufacturing and service processes.
\end{abstract}

Key words: management, LCA, six sigma, quality, environment

\section{INTRODUCTION}

Globalization and instant access to information, products and services continue to change the way of customers conduct business. Current policy changes, in the economy and society, should be carried out in accordance with the principles of sustainable development and environmental protection. Therefore, our country introduces a series of voluntary environmental tools and methods such as environmental audits, Environmental Management Systems (EMS according to ISO 14001 ), environmental assessment and labeling of products, Life Cycle Assessment (LCA), ecological profile of the product and the like. With their introduction, the organizations create the way for a balanced and integrated approach in terms of economic, quality, environmental and security interests. One of the major tools used in practice, especially abroad, is Six Sigma, whose implementation was gradually promoted in business also in Slovakia.

\section{CONCEPTS OF SIX SIGMA}

The word „Sigma“ is a statistical term that measures how far a given process deviates from perfection as a new methodology ussing old tools. Six Sigma is a comprehensive system for achieving, maintaining and maximizing business success. The basis of Six Sigma is a detailed knowledge of customer requirements, disciplined use of facts and objective data, statistical analysis and ongoing efforts focused on optimizing business processes. Six Sigma revolves around a few key concepts :

1. Critical to Quality: Attributes most important to the customer

2. Defect: Failing to deliver what the customer wants

3. Process Capability: What your process can deliver

4. Variation: What the customer sees and feels

5. Stable Operations: Ensuring consistent, predic-table processes to improve what the customer sees and feels

6. Design for Six Sigma: Designing to meet customer needs and process capability

\section{PHILOSOPHY AND METHODOLOGY OF IMPROVEMENT BY SIX SIGMA METHOD}

It is said, that philosophy and methodology of Six Sigma improvement is a revolution in increasing the efficiency of organizations. In recent years, it has become popular not only among specialists in the field of process improvement, but was also common on the board of directors and senior management of the world's largest industrial companies, as well as in programs improving services in banks and hospitals. It has much in common with its predecessors, while there is a new approach in the organization and standardization process improvement projects and measuring their benefits. Six Sigma is a method of improving productivity, efficiency and quality of products and services. Based on perfect understanding of the requirements and expectations of customers and apply proven tools to eliminate errors in processes leading to their satisfaction. Six Sigma is implemented through its own employees. The involved employees represent the most important capacity of improvements. Focusing on customers, processes and staff makes Six Sigma a way of building and developing a new corporate culture. The method Six Sigma is a high technological method used by engineers and statisticians to fine-tune products and processes. But that's just a part of the truth. Six Sigma presents a measurement and statistics as an essential part of improving. It aims to nearly complete coverage of all customer expectations. The term Six Sigma is derived from the mode of a control process, which shows less than 3.4 defects per million opportunities. Six Sigma is mainly based on understanding customer needs and expectations, using the facts, data and statistical analysis and a thorough approach to managing, improving and creating new business, production and service processes. Six Sigma in particular focuses on:

- Method of measuring quality, which allows you to compare different processes according to the achieved level SIGMA - variability of process (http://www. adamssixsigma.com/);

- Project-oriented methodology for solving problems using statistical tools;

- The quality improvement system, aimed at reducing errors and maintaining them at a low value, "Six sigma", meaning DPMO (DPMO = Defects per Million Opportunities);

- Philosophy and managerial strategy oriented on customer satisfaction and making decisions based on verified data.

\section{CHOSEN SIX SIGMA METHODS}

Six Sigma is based on six basic principles that help with launching the initiative implementation of Six Sigma method to production companies or service industries. Sigma uses the base tools to improve the quality of products and processes as MSA (Measurement System Analysis), IPO Diagram (Inputprocess-output), CE (Cause-and-effect diagram), Histogram, Pareto diagram, DMAIC (Define, Measure, Analyze, Improve, Control), Run chart, Control chart, Scatter diagram, Regression Analysis, DOE (Desing of Experiments), FMEA (Failure Mode and effect analysis), SOP (Standard Operating Procedure), QFD (Quality Function Deployment.

\subsection{Measurement System Analysis}

Diffusion of watched commoditie's parameter can be connected by the commodity itself (deformation, ovality) or the system of measuring. The system of measuring is made by operator, benchmark and the method - the way of measuring. Measuring Systém analysis (MSA) is a tool for evaluation of the accuracy and advisability of the measuring system. It goes with testing/measuring the chosen parameter by operator or a 
group of operators. It watches the influence of repeatance (one operator copies the measuring of watched commoditie's parameter) and reproducibility (group of operators measures the very same parameter) of the total variance. The goal of MSA is to estimate how the system of measuring contributes to the total variance of watched parameter, Fig.1 (http://www. sixsigma. $\mathrm{sk} /$ ). Most of the time is analysis of the measurement system used in the phase Measurements.

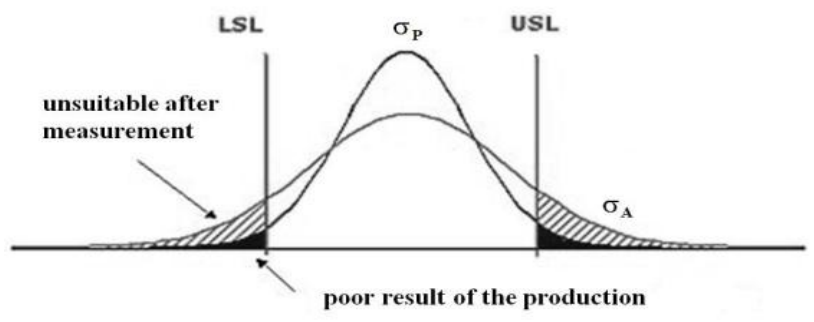

Fig. 1. Measurement System Analysis

Legend: Tolerance $=$ USL - LSL (area of matching values for the customer), LSL - Lower, USL - Upper Specification Limit, $\sigma_{A}^{2}$ - absolute variance), $\sigma_{P}^{2}$-product variance.

\subsection{Analysis of the causes and consequences}

CE (Cause-and-effect diagram) is a tool to solve problems through finding the cause of their creation. Helps to find all possible causes to differ causes do cathegories and organize their relationship and impact on output and identify opportunities for improvement. In general, these categories are commonly known as causes 7M: (1) Man -people,job; (2) Methods and mechanics, process; (3) Machine - machines, eguipment; (4) Measurement; (5) Management - system of organiation and management; (6) Material; (7) Mother nature environment.

During a more detailed analysis of each factor to get the diagram, the diagramthat reminds a fish bone (the reason for this often used name), seef figure 2 .

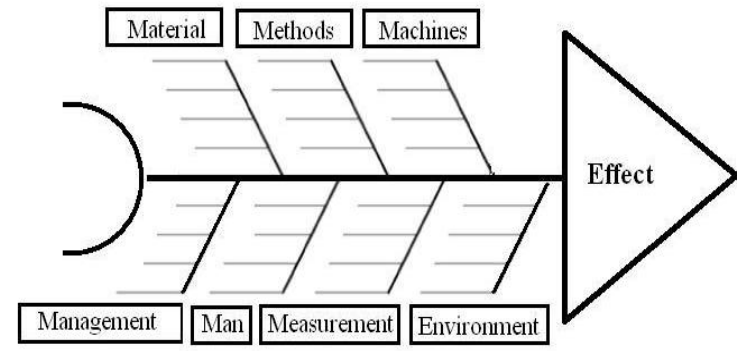

Fig.2. Fish bone 7M diagram

\subsection{Histogram}

Histogram is a tool perfect for visualization of the frequency of the wathced phenomenon in process. It is a bar chart made from number categories, wich shows their splitting. Customer filled tolerance can be added ( LSL, USL) for watched process.

\subsection{DMAIC and DMADV}

DMAIC (Define-Measure-Analyze-Implement-Control) is in the SixSigma metodology being used as the standart routine for planning and realization of the project. Another approach, used when the goal is the development of a new or radically redesigned product, process or service is DMADV (DefineMeasure-Analyze-Design-Verify), Fig. 3 (Pyzdek, T.,2009).

\subsection{Pareto Diagram}

Pareto diagram is a bar chart for discrete data, indicating the frequency of non digital data. These categories are arranged in descending order. The tool that allows determining the impact of input factors to an endpoint.

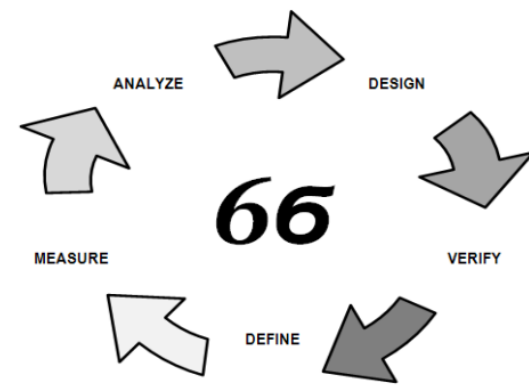

Fig.3. Six Sigma DMADV

\section{IMPLICATIONS FOR ENVIRONMENTAL MANAGEMENT}

Six Sigma method could be applied to EMS design because it has been successfully implemented in many large corporations in order to improve the quality of products and business processes. The company noted that while Lean Six Sigma projects focused on improving operational efficiency and product field, direct reductions in energy use, air emissions, waste reduction, greenhouse gas emissions, and other environmental impacts also coincided. The implication of environmental performance lines to reduction of the overall environmental impacts.

Potential benefits: By removing variation from production processes are less-defect internal results. A reduction in defects can, in turn, help eliminate waste from processes in three fundamental ways:

1. fewer defects decreases the number of products that must be scrapped;

2. fewer defects also means that the raw materials, energy, and resulting waste associated with the scrap are eliminated;

3. fewer defects decreases the amount of energy, raw material, and wastes that are used or generated to fix defective products that can be re-worked.

Six Sigma are the tools which help focus attention on reducing conditions that can result in accidents, spills, equipment malfunctions, reduce the solid and hazardous wastes (e.g., contaminated rags and adsorbent pads) resulting from spills and leaks and their clean-up. This method is focus on product durability and reliability to increase the life cycle of products.

Potential disadvantagies: Lack of technical capacity to effectively utilize Six Sigma tools can potentially decrease effectiveness of the strategy, and/or result in unexpected waste if bad applied.

\section{CONCLUSION}

One of the major tools used in practice, especially abroad is Six Sigma, whose implementation was gradually promoted in business also in Slovakia. The paper is result of research in the frame of national grant No 3/7422/09 "Creating of research conditions for preparation of modern university text book".

\section{REFERENCES}

Samuelson, P.A. - Nordhaus,W.D. (2000). Economy. Bratislava. 822 p., ISBN 80-8044-059-X

Sauer, P. - Livingston, M. (1996). Environmental economy and ecology police, Prague, 203 p., ISBN 80-902168-0-3

Kozakova, L. - Zelenak, F. (2007): Wastes and their disposal, WILLCOM - Košice, ISBN 978-80-8073-849-5. 125 p

Kralikova, R.-Paulikova, A. (2008): Modelling and diagnosing of mechanical engineering life cycle production process. In: Chemicke listy. Vol. 102 (S). Prague, ISSN 0009-2770

***(2007) FBE Bratislava: http://www.sixsigma.sk/2011-02-15

***(2006) Adams Six Sigma: http://www. adamssixsigma.com/ Accessed on: 2011-02-15

***(2009) http://www.pyzdek.com/ Accessed on: 2011-01-10 